\title{
Akıllı Şehirler için Özellik Çıkarımı ve Makine Öğrenmesi Tabanlı Asfalt Durum İzleme Yaklaşımı
}

\author{
Mehmet Bayğın ${ }^{1 *}$, Orhan Yaman², Türker Tuncer ${ }^{3}$ \\ 1* Ardahan Üniversitesi, Mühendislik Fakültesi, Bilgisayar Mühendisliği Bölümü, Ardahan, Türkiye, (ORCID: 0000-0002-5258-754X), mehmetbaygin@ ardahan.edu.tr \\ ${ }^{2}$ Fırat Üniversitesi, Teknoloji Fakültesi, Adli Bilişim Mühendisliği Bölümü, Elazığ, Türkiye (ORCID: 0000-0001-9623-2284), orhanyaman@ firat.edu.tr \\ ${ }^{3}$ Frrat Üniversitesi, Teknoloji Fakültesi, Adli Bilişim Mühendisliği Bölümü, Elazı̆̆̆, Türkiye (ORCID: 0000-0002-5126-6445), turkertuncer@ firat.edu.tr
}

(İlk Geliş Tarihi 21 Aralık 2020 ve Kabul Tarihi 12 Mart 2021)

(DOI: $10.31590 /$ ejosat.844592)

ATIF/REFERENCE: Bayğın, M., Yaman, O. \& Tuncer, T. (2021). Akı1lı Şehirler için Özellik Çıkarımı ve Makine Öğrenmesi Tabanlı Asfalt Durum İzleme Yaklaşımı. Avrupa Bilim ve Teknoloji Dergisi, (23), 81-88.

\section{$\ddot{O} \mathbf{z}$}

Karayolu taşımacılığ̣ günümüzde sıklıkla kullanılan bir taşımacılık yöntemi olup, araçların daha güvenlikli bir yolculuk yapabilmesi amacıyla sürekli gelişim göstermektedir. Karayollarında kullanılan temel kaplama malzemesi asfalttır. Asfalt malzemesi ise özellikle başta zaman olmak üzere, yoğun trafik kullanımına bağlı olarak deforme olabilmekte ve yıpranmaktadır. Bu çalışma deforme olan ve yıpranan asfaltı görüntü işleme yöntemiyle tespit etmeyi ve sağlam-arızalı olarak sınıflandırmayı amaçlamaktadır. Bu amaçla bir karayolu aracına monte edilen kamera ile toplam 3912 adet asfalt görüntüsü toplanmıştır. Öncelikle bu görüntülere ortalama havuzlama yöntemi uygulanmış ve görüntüler bir ön işlemeye tabi tutulmuştur. Bu algoritma ile görüntülerde boyut azaltma işlemi yapılmıştır. Ön işleme adımından sonra yönlendirilmiş gradyan histogramı (HOG) yöntemi kullanılarak görüntülerden özellik çıkarımı yapılmıştır. Bu işlemden sonra Ki-Kare yöntemi ile özellik seçimi uygulanmış ve ağırlıklı öz nitelikler elde edilmiştir. Son olarak elde edilen bu özellikler destek vektör makinleri (SVM) yöntemi kullanılarak sınıflandırılmış ve elde edilen sonuçlar performans yönünden değerlendirilmiştir. Performans metrikleri olarak doğruluk, kesinlik, duyarlılık, geometrik ortalama ve f-skor değerleri hesaplanmıştır. Önerilen yöntem sonucunda \%96.5 oranında bir doğruluk elde edilmiştir. Çalışma kapsamında test edilen yöntemin uygulanmasıyla asfalt kaplama malzemesinin insan müdahalesine gerek kalmadan yıpranma durumunun anlaşılabileceği ortaya koyulmuştur. Dolayısıyla, sürekli kontrolün oldukça zor olduğu bu işlemde makine öğrenmesi tabanlı otomatik arıza tespit yöntemi kullanılabilir. Bu sayede daha güvenli bir sürüş deneyimi yaşanması için asfalt bakım ve onarım giderlerinin azaltılmasına katkıda bulunulmuştur. Elde edilen sonuçlar, literatür ışı ğında tartışılmış ve yöntemin başarısı literatürle de desteklenmiştir.

Anahtar Kelimeler: Asfalt durum izleme, arıza tespiti, HOG özellik çıkarımı, SVM sınıflandırma.

\section{Feature Extraction and Machine Learning Based Pavement Condition Monitoring Approach for Smart Cities}

\begin{abstract}
Road transport is a transportation method that is frequently used today, and it is constantly evolving in order for vehicles to travel more safely. The basic coating material used on highways is asphalt. Asphalt material can deform and wear out due to heavy traffic use, especially over time This study aims to detect deformed and worn asphalt with image processing method and classify it as healty or faulty. For this purpose, a total of 3912 asphalt images were collected through a camera mounted on a road vehicle. First of all, the average pooling method was applied to these images and the images were subjected to a pre-processing. With this algorithm, size reduction was performed on the images. After the pre-processing step, feature extraction from the images was made using the Histogram of Oriented Gradients (HOG) method. After this process, feature selection was applied with the Chi-Square method and
\end{abstract}

*Sorumlu Yazar: mehmetbaygin@ardahan.edu.tr 
the most weighted attributes were obtained. Finally, these features were classified using Support Vector Machines (SVM) method and the results obtained were evaluated in terms of performance. Accuracy, precision, recall, geometric mean and f-score values were calculated as performance metrics. As a result of the proposed method, an accuracy of $96.5 \%$ was obtained. By applying the method tested within the scope of the study, it has been revealed that the wearing of the asphalt coating material can be understood without human intervention. Machine learning based automatic fault detection method has been developed in this process where continuous control is very difficult. In this way, it has contributed to the reduction of asphalt maintenance and repair costs for a safer driving experience. The results obtained were discussed in the light of the literature and the success of the method is supported by the literature.

Keywords: Asphalt condition monitoring, fault detection, HOG feature selection, SVM classification.

\section{Giriş}

Karayolu taşımacılığı günümüzde ulaşım sektöründe sıklıkla kullanılan en önemli taşımacılık yöntemidir. Hafif ve ağır vasıta araçlar kullanılarak gerek yolcu gerekse yük taşımacılığı genellikle karayolu ile yürütülmektedir. Günümüzde karayollarında kullanılan temel kaplama malzemesi asfalttır ve asfalt malzemesi yapısı gereği zaman içerisinde bazı sebeplerden dolayı bozulmaya uğramaktadır (Gopalakrishnan et al., 2017). Özellikle trafik yoğunluğunun fazla olduğu bölgelerde bu durum daha sık gözlemlenmektedir. Ayrıca ağır vasıta araçların yoğun olarak kullanıldığı yollarda, asfalt yüzeyinde aşırı yükten dolayı meydana gelen bozulma, çatlama ve çökme gibi durumlar oluşabilmektedir (Some, 2016). Asfalt kaplama yüzeyinde kısa zamanda bozulmaya sebebiyet veren bir diğer durum ise gece gündüz sıcaklık farkının yoğun olarak yaşanmasıdır. Özellikle k1ş dönemlerinde meydana gelen bu durum neticesinde asfalt yüzeylerinde yoğun çatlaklar meydana gelebilmektedir. $\mathrm{Bu}$ ve benzeri durumlar sürücülere sürüş güvenliği noktasında büyük tehdit oluşturmaktadır (Bello-Salau et al., 2016; Shi et al., 2016). Ayrıca bu gibi durumların önceden tespit edilememesi neticesinde yüksek bakım maliyetleri meydana gelmektedir (Kawano et al., 2017).

\subsection{Motivasyon}

Makine öğrenmesi algoritmaları günümüzde sıklıkla kullanılan ve başta sınıflandırma olmak üzere birçok farklı alanda başarılı sonuçlar elde edilmesini sağlayan yöntemler bütünüdür. Gerçekleştirilen bu çalışmada da otomatik asfalt arıza tespitine yönelik bir yöntem geliştirilmiştir. Bu amaçla aktif olarak kullanılan asfalt kaplamalı yollardan 3912 adet görüntü toplanmış ve bir veri seti oluşturulmuştur. Daha sonra bu veri setinden özellik çıkarımı yapılmış ve elde edilen özellikler özellik seçim algoritmasına gönderilmiştir. Bu noktada en ağırlıklı özelliklerin seçimi yapılmış ve elde edilen ağırlıklı özellikler SVM algoritması kullanılarak sınıflandırılmıştır. Temel olarak sağlıklı ve arızalı görüntülerin sınıflandırıldığı bu yaklaşımda, asfalt durum izlemeye yönelik otomatik ve yüksek doğruluklu bir yöntem geliştirilmiştir. Ayrıca yöntemin performansı değerlendirildiğinde önerilen yaklaşımın \%96.5 oranında bir verim sağladığı gözlemlenmiştir.

\subsection{Literatür Özeti}

Asfalt durum izleme konusu literatürde çalışılan önemli konuların başında gelmektedir. Gerek inşaat alanında gerekse bilgisayar bilimlerinde bu konu sıklıkla çalışılmakta ve asfalt durum izlemeye yönelik çeşitli yöntemler geliştirilmektedir. Karayollarında kullanılan temel kaplama malzemelerinden birisi olan asfalt çeşitli sebeplerden dolayı bozulmaya uğramakta ve bu durumda başta sürüş güvenliği olmak üzere birçok probleme sebebiyet vermektedir (Jahanshahi et al., 2013). Bu sebepten asfalt durumunun sürekli gözetim altında tutulması, arızaların erken tespit edilmesi ve bu kaplama malzemesinin onarılmas son derece önemli bir konudur. $\mathrm{Bu}$ konu üzerine literatürde yapılmış çeşitli çalışmalar bulunmaktadır. Asfalt yüzeylerinin incelendiği bu çalışmalarda kullanılan yöntemlerin başında da makine öğrenmesi gelmektedir. Literatürde bu konuda yapılan bazı çalışmalar Tablo 1'de verildiği gibidir.

\section{Tablo 1. Literatürde Yapılan Çalışmaların Özeti}

\begin{tabular}{|c|c|}
\hline Çalışmalar & Kısa Özet \\
\hline $\begin{array}{l}\text { Nguyen et } \\
\text { al.(Nguyen et al., } \\
2011 \text { ) }\end{array}$ & $\begin{array}{l}\text { Gerçekleştirilen bu çalışmada asfalt görüntülerinde çatlak tespiti için segmentasyon adımında } \\
\text { parlaklık ve bağlanabilirliği dikkate alan yeni bir yöntem önerilmiştir. Serbest biçimli yol boyunca } \\
\text { özellik çıkarımı sağlanmış ve bazı çatlak türleri tespit edilmiştir. Çalışmada ortalama \%78 başarı } \\
\text { sağlanmıştır. }\end{array}$ \\
\hline $\begin{array}{l}\text { Fan et al. (Fan et } \\
\text { al., 2020) }\end{array}$ & $\begin{array}{l}\text { Bu çalışmada, otomatik asfalt tespiti ve ölçümü için olasılık füzyonuna dayanan bir konvülüsyonel } \\
\text { sinir ağı yöntemi önerilmiştir. Çalışmada } 2 \text { farklı veri seti kullanılmış olup, kullanılan veri setleri } \\
\text { üzerinde ortalama } \% 94 \text { başarı sağlanmıştır. }\end{array}$ \\
\hline $\begin{array}{l}\text { Xu et al. (Xu \& } \\
\text { Tang, 2013) }\end{array}$ & $\begin{array}{l}\text { Çalışma kapsamında asfalt çatlakları için eğiticisiz çatlak tespit yaklaşımı önerilmiştir. Belirginlik } \\
\text { ve istatistiğe dayalı yöntemlerin kullanıldığı bu çalışmada } 261 \text { çatlak görüntüsü toplanmış ve } \\
\text { önerilen yöntem bu görüntüler üzerinde test edilmiştir. Çalışmada \%89 başarı elde edilmiştir. }\end{array}$ \\
\hline $\begin{array}{l}\text { Cheng et } \\
\text { al.(Cheng et al., } \\
\text { 2019) }\end{array}$ & $\begin{array}{l}\text { Konu üzerine yapılan bu çalışmada derin evrişimli sinir ağı (U-Net) kullanılarak otomatik çatlak } \\
\text { tespit yöntemi önerilmiştir. U-Net'in encoder-decoder mantığının kullanıldığı bu çalışmada test } \\
\text { verisi olarak } 2 \text { farklı veri kümesi kullanılmıştır. Önerilen yöntem her iki veri kümesi içinde } \\
\text { ortalama } \% 92 \text { başarı sağlamıştır. }\end{array}$ \\
\hline $\begin{array}{l}\text { Zhang et al. } \\
\text { (Zhang et al., } \\
\text { 2017) }\end{array}$ & $\begin{array}{l}\text { Otomatik asfalt çatlak tespitine yönelik gerçekleştirilen bu çalışmada Region of Belief (ROB) adı } \\
\text { verilen yeni bir kavram önerilmiştir. Çalışma kapsamında geliştirilen uygulamada ilk olarak alınan } \\
\text { görüntüler piksel değerlerine göre kümelendirilmiştir. Daha sonra bu kümelere eşikleme yöntemi }\end{array}$ \\
\hline
\end{tabular}




\begin{tabular}{|c|c|}
\hline & $\begin{array}{l}\text { uygulanmış ve görüntü segmentasyonu işlemi gerçekleştirilmiştir. Son olarak ROB adıverilen ve } \\
\text { çalışma çerçevesinde önerilen yaklaşım uygulanmış ve çatlaklar tespit edilmiştir. Toplam } 10000 \\
\text { görüntünün kullanıldığı bu çalışmada \%95'in üzerinde başarı oranı sağlanmı̧̧ır. }\end{array}$ \\
\hline $\begin{array}{l}\text { Majidifard et } \\
\text { al.(Majidifard, } \\
\text { Adu-Gyamfi, et } \\
\text { al., 2020) }\end{array}$ & $\begin{array}{l}\text { Gerçekleştirilen bu çalışmada Google Street View uygulaması kullanılarak çeşitli asfalt } \\
\text { görüntüleri toplanmış ve geliştirilen uygulamada eğitim ve test amaciyla bu görüntüler } \\
\text { kullanılmıstır. } 9 \text { türde problemin incelendiği bu çalı̧̧mada toplanan görüntüler kusur durumlarına } \\
\text { göre etiketlenmiştir. YOLO ve U-Net derin öğrenme framework'lerinin kullanıldığı bu çalışmada } \\
7237 \text { görüntü kullanılmış olup, oldukça başarılı sonuçlar elde edilmiştir. }\end{array}$ \\
\hline $\begin{array}{l}\text { Zalama et al. } \\
\text { (Zalama et al., } \\
\text { 2014) }\end{array}$ & $\begin{array}{l}\text { Bu çalışmada yazarlar tarafından boyuna ve enine çatlaklar tespit edilmeye çalışılmıştır. Gabor } \\
\text { filtresi tabanlı bu yöntemde sınıflandırıcıların eşik değerlerini ayarlamak için } 3 \text { farklı yöntem } \\
\text { kullanılmıstır. Çalışmada son olarak AdaBoost algoritması kullanılarak sınıflandırıcıların seçimi } \\
\text { ve birleştirilmesi işlemi yapılmıştır. Bu sayede tek bir sınıflandırıcı kullanılarak veri seti } \\
\text { incelenmiştir. Kullanılan veriler bir araca yerleştirilen kamera ve gps cihazı ile elde edilmiştir. }\end{array}$ \\
\hline $\begin{array}{l}\text { Shahnazari et } \\
\text { al.(Shahnazari et } \\
\text { al., 2012) }\end{array}$ & $\begin{array}{l}\text { Gerçekleştirilen bu çalışmada asfalt durumunu tanımlamak için kullanılan parametrelerden birisi } \\
\text { olan Asfalt Durum Indeksi (PCI) tahmin edilmeye çalş̧ılmıştır. Yumuşak hesaplama } \\
\text { tekniklerinden olan Genetik programlama ve Yapay sinir ağları uygulamada kullanılmıştır. Iran } \\
\text { bölgesinde } 1250 \text { km'lik karayolundan alınan görüntülerin kullanıldığı bu çalışmada yapay sinir ağ } 1 \\
\text { ve genetik programlama için ayrı modeller oluşturulmuş ve test edilmiştir. Test sonuçları yapay } \\
\text { sinir ağının daha doğru tahmin verdiğini göstermiştir. }\end{array}$ \\
\hline $\begin{array}{l}\text { Mandal et al. } \\
\text { (Mandal et al., } \\
\text { 2019) }\end{array}$ & $\begin{array}{l}\text { Konu üzerine gerçekleştirilen bu çalışmada derin evrişimli sinir ağları kulanılarak otomatik yol } \\
\text { çatlak tespiti geliştirilmiştir. Çalışmada YOLO v2 derin öğrenme modeli kullanılmış ve otomatik } \\
\text { analiz sistemi yapılmıştır. Sistem } 7240 \text { görüntü ile eğitilmiş ve } 1813 \text { yol görüntüsü ile test } \\
\text { edilmiştir. Çalışmada yaklaşı } \% 87 \text { oranında bir performans elde edilmiştir. }\end{array}$ \\
\hline $\begin{array}{l}\text { Baoxian et al. ( } \mathrm{Li} \\
\text { et al., 2020) }\end{array}$ & $\begin{array}{l}\text { Bu çalışmada da bir öncekine benzer şekilde derin sinir ağları kullanılmış olup, çatlak tespitinde } \\
\text { otomatik sınıflandırma işlemi yapılmıştır. Evrişimli sinir ağının kullanıldığı bu çalışmada \%94'ün } \\
\text { üzerinde bir başarı sağlanmıştır. }\end{array}$ \\
\hline $\begin{array}{l}\text { Majidifard et al. } \\
\text { (Majidifard, Jin, } \\
\text { et al., 2020) }\end{array}$ & $\begin{array}{l}\text { Bu çalışmada da Google Street View uygulamasından toplanan } 7237 \text { adet asfalt kategorisi } 9 \text { farklı } \\
\text { sınıf için sınıflandırma işlemine tabi tutulmuştur. Derin öğrenmenin kullanıldığı bu yaklaşımda } \\
\text { YOLO v2 ve Faster R-CNN derin öğrenme modelleri kullanılmıştır. Doğruluk skorları YOLO v2 } \\
\text { için } 0.84 \text { ve Faster R-CNN modeli için } 0.65 \text { elde edilmiştir. }\end{array}$ \\
\hline
\end{tabular}

\subsection{Yöntem}

$\mathrm{Bu}$ çalışmada arızalı asfaltın tespit edilmesi ve sağlamarızalı şeklinde sınıflandırılabilmesi amacıyla görüntü işleme yöntemi kullanılmıştır. Bu amaçla asfalt durumunu analiz etmek için 3912 adet farklı görüntü kullanılmış ve elde edilen bu görüntüler sınıflandırılmıştır. Önerilen yaklaşımda ilk olarak görüntü ön işleme adımlarından birisi olan ortalama havuzlama yöntemi kullanılmış ve 360x640 çözünürlüğe sahip her bir görüntü karesi 90x160 çözünürlüğe indirilmiștir. Bu işlemin temel amacı görüntü boyutlarını küçültmek ve buna bağlı işlem süresini azaltmaktır. Bu işlemin ardından boyutu azaltılmış görüntülere HOG algoritması uygulanmaktadır. Bu yöntem ile her bir görüntüden özellik çıkarımı yapılmakta ve elde edilen özellikler kaydedilmektedir. $\mathrm{Bu}$ aşama sonucunda toplam 3912 x6840 boyutuna sahip bir özellik matrisi elde edilmektedir. Elde edilen bu özellik matrisinde en ağırlıklı özelliklerin seçilmesi gerekmektedir. Bu sayede özellik matrisinin boyutu azaltılacak ve daha doğru sonuç elde edilmesi sağlanacaktır. Normalde HOG işlemi ile her bir görüntü karesinde toplam 6840 özellik elde edilmiştir. Özellik seçiminde uygulanan Ki-kare yöntemi sonucunda ise her bir görüntü karesi için bu sayı 443'e indirilmiş ve toplamda 3912x443 boyutunda ağırlıklandırılmış bir özellik matrisi elde edilmiştir. Elde edilen özellik matrisinin sınıflandırılması için SVM yöntemi kullanılmıştır. Bu noktada Lineer SVM, Quadratik SVM, Cubic SVM, Medium Gaussian SVM ve Cuarse Gaussian SVM yöntemleri özellik matrisine uygulanmış ve elde edilen sonuçlar gözlemlenmiştir. Tüm görüntüler için elde edilen sonuçlar karmaşıklık matrisine aktarılmış ve doğruluk, kesinlik ve duyarlılık değerleri hesaplanmıştır.

\subsection{Sunulan Katkılar ve Yenilikler}

Önerilen yöntemin sunduğu katkılar ve yenilikleri aşağıda verildiği gibidir;

- Çalışma kapsamında 3912 farklı asfalt görüntüsü toplanmış ve HOG algoritması ile özellik çıkarımı yapılmıştır.

- Elde edilen özelliklere Ki-kare yöntemi uygulanarak ağırlıklı özellikler tespit edilmiş ve başarı oranı arttırılmıştır.

- Seçilen ağırlıklı özelliklerin SVM yöntemi kullanılarak sınıflandırılması sağlanmış ve \%96.5 oranında bir doğruluk elde edilmiştir.

- Önerilen yöntemde kullanıcı müdahalesine gerek kalmayan tam otomatik bir durum izleme yaklaşımı geliştirilmiştir.

\section{Materyal ve Metot}

Önerilen yaklaşımın ilk aşamasında veri seti oluşturulma işlemi uygulanmıştır. $\mathrm{Bu}$ amaçla hareket halinde bir araca kamera yerleştirilmiş ve bu kamera aracılığıyla seyahat halinde iken görüntü toplanmıştır. Görüntüler belirli aralıklarda ve farklı asfalt kaplamaya sahip çeşitli karayollarından alınmıştır. Seyahat öncesinde kamera aracın ön tamponuna monte edilmiş ve geniş 
açıyla asfaltı kaydedebilecek pozisyona getirilmiştir. Bu sayede sağlam ve problemli asfalt görüntülerinn toplanması amaçlanmıştır. Görüntülerin toplanması sürecinde ise bir aksiyon kamerası kullanılmış olup, kullanılan bu kameraya ait bazı temel özellikler Tablo 2'de sunulmuştur.

Tablo 2. Asfalt Görüntülerinin Toplanmasında Kullanılan Aksiyon Kamera Özellikleri

\begin{tabular}{|c|c|}
\hline Parametre & Değer \\
\hline Slvı kristal ekran & 2.0 LCD ekran \\
\hline Görüntü sensörü & 12 megapiksel CMOS sensörü \\
\hline $\begin{array}{c}\text { Kaydedilen videonun } \\
\text { çözünürlüğ̈ü }\end{array}$ & $\begin{array}{c}4 \mathrm{~K} 25 \mathrm{FPS} \\
2.7 \mathrm{~K} 30 \mathrm{FPS} \\
1080 \mathrm{P}(1920 * 1080) 60 \mathrm{FPS} / 30 \mathrm{FPS} \\
720 \mathrm{P}(1280 * 720) 120 \mathrm{FPS} \\
\end{array}$ \\
\hline Lens & $170+$ HD geniş açılı lens \\
\hline Videoların formatı & H.264 \\
\hline $\begin{array}{l}\text { Fotoğrafların } \\
\text { çözünürlüğ̈̈ }\end{array}$ & $12 \mathrm{M} / 8 \mathrm{M} / 5 \mathrm{M} / 2 \mathrm{M}$ \\
\hline Zaman aşımı & Kapal1/2s/3s/5s/10s/20s/30s/60s \\
\hline Optik kaynak frekansl & $50 \mathrm{~Hz} / 60 \mathrm{~Hz} /$ otomatik \\
\hline Pil kapasitesi & $1050 \mathrm{MAH}$ \\
\hline Boyut & $59.3 * 24.6 * 41.1 \mathrm{~mm}$ \\
\hline
\end{tabular}

Çalışma kapsamında kullanılan aksiyon kamerasının monte edildiği araç ile görüntü alınacağı süreçte seyahat edilmiştir. Araçta mevcut bulunan hız sabitleyici sayesinde ort. $80 \mathrm{~km} / \mathrm{s} \mathrm{hız}$ sağlanmış olup, seyahat süresince kameranın video kayıt yapması sağlanmıştır. Çalışmada kullanılan kamera saniyede 30 görüntü karesi (fps) alacak şekilde ayarlanmıştır. Görüntü toplama sürecinin ardından kameraya kaydedilmiş görüntüler bilgisayar ortamına aktarılmış ve bu görüntülere seçim işlemi uygulanmıştır. $\mathrm{Bu}$ seçimin ardından toplam 3912 görüntü elde edilmiş ve bu görüntüler işlenmek üzere bir sonraki aşamaya aktarılmıştır. Çalışma kapsamında seçilen ve kullanılan (a) sağlıklı ve (b) arızalı asfalt durumlarına ait bazı örnek görüntüler Şekil 1'de verildiği gibidir.
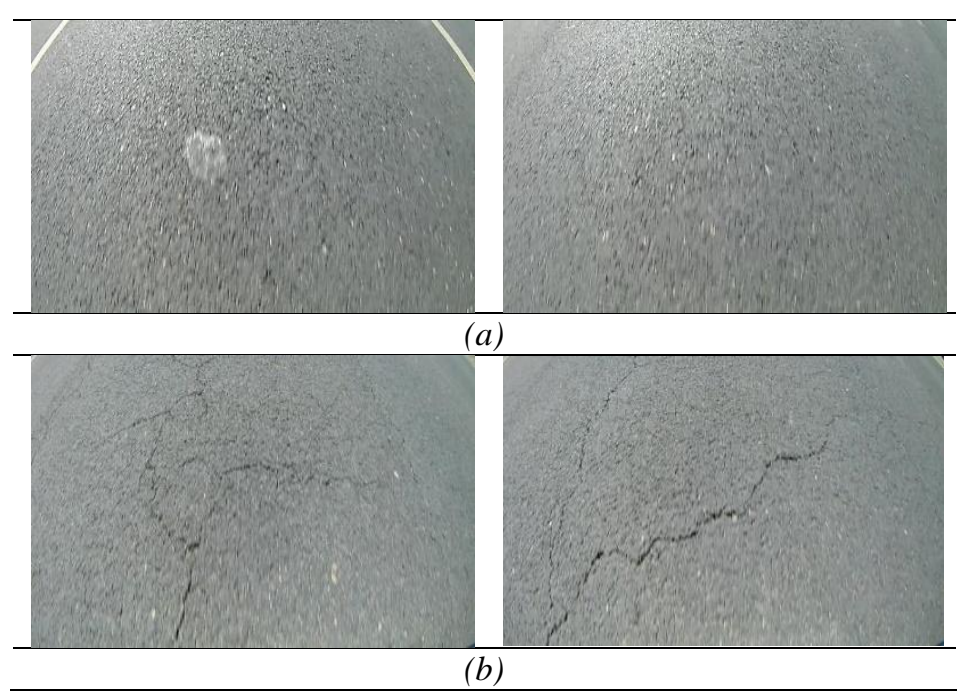

Şekil 1. Örnek Sağlıklı ve Arızalı Asfalt Görüntüleri (a) Sağlıklı Asfalt Görüntüleri (b) Arızalı Asfalt Görüntüleri

\section{3. Önerilen Yöntem}

Çalışma kapsamında asfalt durum izlemeye yönelik otomatik sınıflandırma yapabilen bir yöntem geliştirilmiştir. Geliştirilen bu yöntemi özetleyen bir akış diyagramı Şekil 2'de sunulmaktadır. Ayrıca bu yöntemde kullanılan aşamaların detayları alt bölümler halinde verilmiştir.

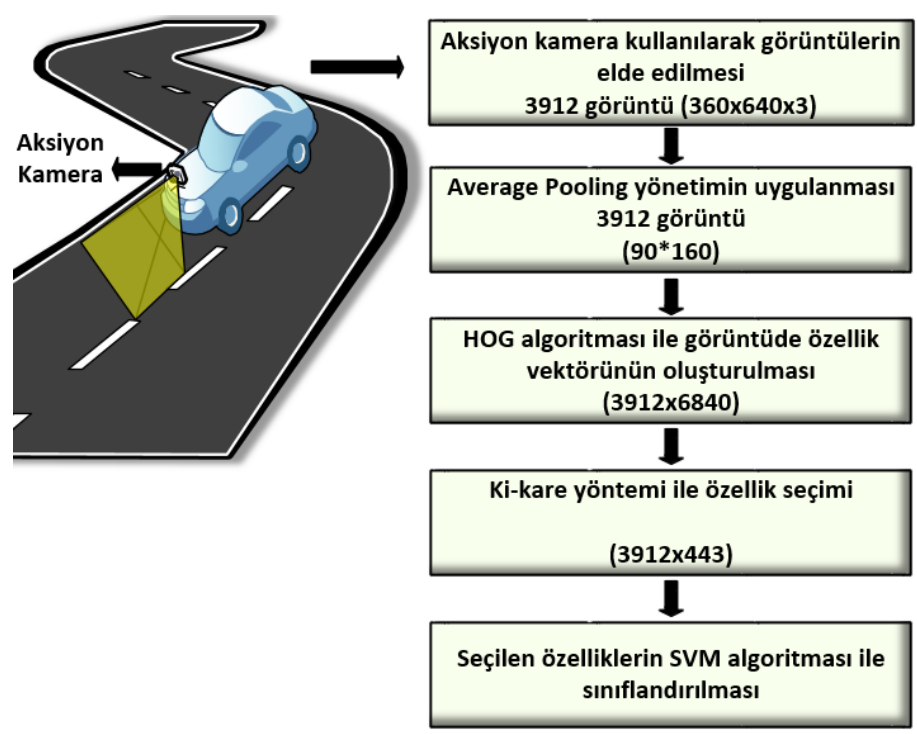

Şekil 2. Önerilen Yöntemin Grafiksel Özeti ve Akış Diyagramı

\subsection{Ortalama Havuzlama Yöntemi}

Ortalama havuzlama yöntemi temel olarak büyük boyutlu bir görüntüde ham görüntüyü bozmadan boyut küçültme işlemidir. Genellikle derin öğrenme yöntemlerinde kullanılan bu işlemde görüntüdeki piksellerin belirli bir kernel boyutuna göre ortalamas1 alınmaktadır. Genelde $2 \times 2$ veya $3 \times 3$ gibi kernel boyutlarının seçildiği bu işlemde, ana görüntüde belirli adım atma değerine göre filtre gezdirilmekte ve görüntüdeki piksellerin ortalaması alınarak yeni piksel değeri oluşturulmaktadır. Bu işlemi özetleyen bir blok diyagram Şekil 3'de sunulmuş olup, yine bu işlemin matematiksel karşılığı Denklem 1'de verilmiştir.

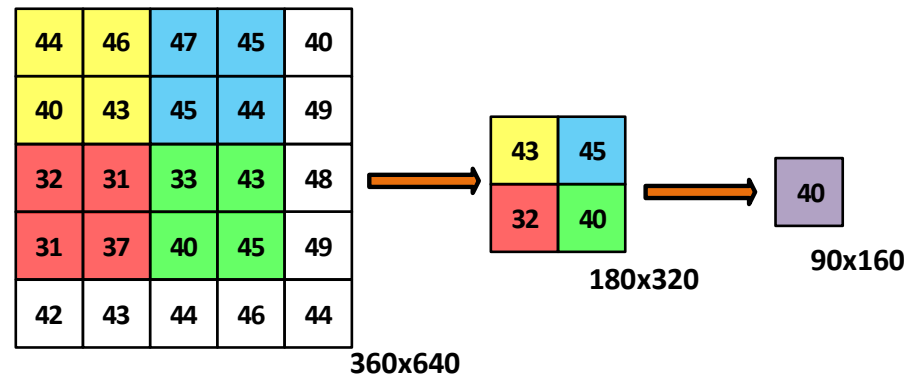

Şekil 3. Ortalama Havuzlama Yöntemi ile Görüntüde Boyut Azaltma

$$
y=\frac{1}{h w} \sum_{i, j=1}^{h, w} p_{i, j}
$$

Denklem 1'de verilen $h$ ve $w$ değerleri kullanılan kernelin boyutlarını gösterirken $p_{i, j}$ değeri ise kernel içerisinde kalan ve hesaplamaya alınacak piksel değerini ifade etmektir. $\mathrm{Bu}$ çalışmada ortalama havuzlama yöntemi ile görüntünün boyutu 
küçültülmüştür. Böylece önerilen yöntemin daha hızlı çalışması sağlanmıştır.

\subsection{Yönlendirilmiş Gradyan Histogramı}

Çalışma kapsamında önerilen özellik çıkarım yöntemi HOG algoritmasıdır. $\mathrm{Bu}$ yöntemin temel amacı görüntülerde yer alan nesneleri yüksek başarı oranı ile tanımlayabilmektir. Yöntem ilk olarak görüntüde düşey ve yatay gradyanı hesaplamaktadır (Alpaslan et al., 2012). Bu işlem temelde sobel algoritmasının benzeri olup Denklem 2'de sunulmaktadır (Karakaya et al., 2009). Bu işlemin ardından yatay ve düşey görüntü gradyanları kullanılarak görüntüdeki piksellerin yönelim $(\theta)$ ve büyüklük $(G)$ değerleri elde edilmektedir. Bu değerlerin hesaplanması ise Denklem 3'de verilmektedir. Daha sonra gradyan yönü ve büyüklüğüne göre gradyan histogramı hesaplanmaktadır. Algoritmanın son aşamasında ise bir normalizasyon işlemi uygulanmaktadır. Normalizasyon işleminin temel amacı ise gradyan histogramının 1 şı değişimlerinden etkilenmesini ortadan kaldırmak olup, bu işlemin matematiksel karşılığ Denklem 4'de paylaşılmıştır.

$$
\begin{gathered}
f_{x}(x, y)=I(x+1, y)-I(x-1, y) \quad \forall x \\
f_{y}(x, y)=I(x, y+1)-I(x, y-1) \quad \forall x, y
\end{gathered}
$$

Denklem 2'de verilen $I(x, y),(x, y)$ noktasındaki piksel yoğunluğunu göstermektedir. Ayrıca $f_{x}$ ve $f_{y}$ sirasıyla yatay ve düşey eksendeki görüntü gradyanlarını ifade etmektedir. $\mathrm{Bu}$ gradyan değerleri kullanılarak Denklem 3'de verilen gradyan büyüklükleri $(G)$ ve gradyan yönelimleri $(\theta)$ hesaplanmaktadır.

$$
\begin{gathered}
G(x, y)=\sqrt{f_{x}(x, y)^{2}+f_{y}(x, y)^{2}} \\
\theta(x, y)=\tan ^{-1}\left(\frac{f_{y}(x, y)}{f_{x}(x, y)}\right) \\
h=\frac{v}{\sqrt{|v|^{2}+\varepsilon}} \quad(\varepsilon=1)
\end{gathered}
$$

Burada $v$ özellik vektörünü ifade etmektedir. Öncelikle özellik vektörünün öklid normu (L2-norm) hesaplanmaktadır. Daha sonra özellik vektöründe yer alan değerlerin öklid normuna bölünmesiyle normalize edilmiş histogram değerleri elde edilmektedir. Ayrıca burada kullanılan $\varepsilon$ değeri yaşanabilecek sıfıra bölünme problemini ortadan kaldırmak için kullanılmaktadır.

\subsection{Ki-Kare Özellik Seçim Yöntemi}

Önerilen yaklaşımda kullanılan bir diğer algoritma ise KiKare yöntemidir. $\mathrm{Bu}$ yöntemin kullanılmasının amacı HOG algoritmasından elde edilen özelliklerden en ağırlıklı olanlarının seçilmesidir. Başka bir deyişle çözüme etki edebilecek olası özelliklerden en kaliteli olanlar belirli matematiksel işlemler ile seçilmekte ve sınıflandırma işleminde kullanılmaktadır (Yazıcı et al., n.d.). Gözlemlenen $(O)$ ve beklenen $(E)$ değerlerin ele alındığını Ki-Kare yönteminde değerlerin serbestlik dereceleri (c) belirlenmektedir. Ki-Kare algoritmasının matematiksel karşılığ1 Denklem 5'de verilmektedir.

$$
x_{c}^{2}=\sum \frac{\left(O_{i}-E_{i}\right)^{2}}{E_{i}}
$$

\subsection{Destek Vektör Makineleri}

Gerçekleştirilen bu çalışmada Ki-Kare yöntemi ile elde edilen en ağırlıklı özellikler SVM algoritması kullanılarak sınıflandırılmıştır. Lineer olmayan problemlerde başarılı çözümler sunan bu algoritma literatürde sıklıkla kullanılan makine öğrenmesi yöntemlerinden birisi olup, genellikle tahmin ve sınıflandırma uygulamalarında tercih edilmektedir ( N. Baygin et al., 2019; Yaman et al., 2020). SVM algoritması temel olarak giriş vektörünü bir özellik uzayına dönüştürerek, bu özellik uzayının çıkış vektörü ile ilişkisini hesaplamaktadır. Makine öğrenmesi yöntemlerinden birisi olan SVM algoritmasının matematiksel karşılığı Denklem 6, 7 ve 8'de sunulmaktadır (Chia et al., 2020).

$$
\begin{gathered}
Y=w \varphi(X)+b \\
0.5\|w\|^{2}+C \frac{1}{n} \sum_{i=1}^{n} L_{\varepsilon}\left(y_{\text {tahmin }}, y_{\text {gercek }}\right) \\
L_{\varepsilon}\left(y_{\text {tahmin }}, y_{\text {gercek }}\right) \\
=\left\{\begin{array}{cc}
0, & \text { eğer }\left|y_{\text {tahmin }}-y_{\text {gercek }}\right|<\varepsilon \\
\left|y_{\text {tahmin }}-y_{\text {gercek }}\right|-\varepsilon, & \text { aksi durumda }
\end{array}\right.
\end{gathered}
$$

Burada $Y$ çıkış vektörü olup, $w$ ağırlık vektörü, $\varphi$ kernel vektörü, $X$ giriş vektörü ve $b$ bias terimini ifade etmektedir. Ayrıca $0.5\|w\|^{2}$ düzenleme terimi, $C$ ceza parametresi, $\varepsilon$ SVM'nin marjinini ifade etmektedir.

Bölüm başında da belirtildiği üzere SVM algoritması değişkenler arasındaki bağlantıyı incelemek için kullanılmaktadır. $N$ boyutlu bir uzay oluşturularak noktalar arasındaki sınıflar belirlenmektedir. Gerçekleştirilen bu çalışmada da çeşitli kernel fonksiyonlarına sahip SVM algoritmaları test edilmiştir. Bu kernel fonksiyonları sırasıyla Linear, Quadratic, Cubic ve Gauss SVM algoritmalarıdır. Çalışma kapsamında toplanan görüntülerden elde edilen öz nitelikler MATLAB Classification Learner uygulamasinda mevcut bulunan SVM kernelleri ve algoritmaları kullanılarak test edilmiştir.

\section{Deneysel Sonuçlar}

\subsection{Deneysel Parametreler}

Önerilen yöntem kapsamında sabit hızla hareket eden bir araçtan toplanan asfalt görüntüleri belirli ön işlemlerden geçirilmiş ve görüntülere ait özellikler çıkarılmıştır. Daha sonrasında elde edilen bu görüntüler, makine öğrenmesi yöntemlerinden birisi olan destek vektör makineleri ile sınıflandırılma işlemine tabi tutulmuştur. Sınıflandırma aşamasında Linear, Cubic, Quadratic ve Gauss kernel yöntemlerine sahip SVM kullanılmış olup, bu kernel yöntemlerine ait bazı temel parametreler Tablo 3'de sunulmaktadır.

Çalışma kapsamında geliştirilen bu yaklaşımın test edilmesinde Intel Core i7-3.00 GHz Işlemciye sahip, 32GB ram'li ve Windows 10 işletim sistemine sahip bir bilgisayar kullanılmıştır. Çalışma süresince geliştirilen test uygulamasının kodları MATLAB 2020a ortamında yazılmış olup, sınıflandırma işlemi için MATLAB Classification Learner kütüphanesi kullanılmıştır. 
Table 3. Önerilen Yöntemde Kullanılan Sinıflandırıcıların

\begin{tabular}{|c|c|c|c|}
\hline \multirow[b]{2}{*}{ Parametre } & \multicolumn{2}{|c|}{ Parametreleri } & \multirow[b]{2}{*}{$\begin{array}{l}\text { Manuel } \\
\text { kernel } \\
\text { ölçeği } \\
\end{array}$} \\
\hline & $\begin{array}{l}\text { Kernel } \\
\text { Fonksiyonu }\end{array}$ & $\begin{array}{l}\text { Kernel } \\
\text { ölçekleme } \\
\text { modu }\end{array}$ & \\
\hline Linear SVM & Linear & Auto & 1 \\
\hline $\begin{array}{l}\text { Quadratic } \\
\text { SVM }\end{array}$ & Quadratic & Auto & 1 \\
\hline Cubic SVM & Cubic & Auto & 1 \\
\hline $\begin{array}{l}\text { Medium } \\
\text { Gaussian } \\
\text { SVM }\end{array}$ & Gaussian & Manuel & 21 \\
\hline $\begin{array}{l}\text { Coarse } \\
\text { Gaussian } \\
\text { SVM }\end{array}$ & Gaussian & Manuel & 84 \\
\hline
\end{tabular}

Uygulamanın ilk aşamasında $80 \mathrm{~km} / \mathrm{s}$ hıza sahip bir araca monte edilen kamera ile görüntüler toplanmış ve bu görüntüler incelenerek toplam 3912 kullanılabilir görüntü seçilmiştir. Çalışmada toplanan görüntüler ilk aşamada 360x640 boyutuna sahiptir. Daha sonra elde edilen görüntülere sirasiyla boyut azaltma, özellik çıkarımı, özellik seçimi ve sınıflandırma işlemleri uygulanmış ve önerilen yaklaşımın performansı karmaşıklık matrisi oluşturularak incelenmiştir. Bu performans değerleri ilerleyen bölümlerde detaylı bir şekilde sunulmuştur.

\subsection{Deneysel Sonuçlar}

Çalışma kapsamında önerilen ve geliştirilen yöntemin performansını test edebilmek amacıyla karmaşıklık matrisi oluşturulmuştur. $\mathrm{Bu}$ performans parametreleri Doğru pozitif (TP), Yanlış pozitif (FP), Doğru Negatif (TN) ve Yanlış Negatif (FN) değerlerine göre hesaplanmaktadır (M. Baygin, 2019). Ayrıca performans değerlendirmesi yapılırken istatistik biliminde de sıklıkla kullanılan doğruluk, kesinlik, duyarlılık, geometrik ortalama ve f-skoru kullanılmış olup, bu parametrelerin matematiksel karşıllı̆ı sırasıyla Denklem 9, 10, 11,12 ve 13 'de sunulmaktadır.

$$
\begin{array}{r}
\text { Accuracy }=\frac{T P+T N}{T P+T N+F P+F N} \\
\text { Precision }=\frac{T P}{T P+F P} \\
\text { Recall }=\frac{T P}{T P+F N} \\
\text { Geometric_mean }=\sqrt{\frac{T P * T N}{(T P+F N)^{*}(T N+F P)}} \\
F-\text { Measure }=\frac{2 T P}{2 T P+F P+F N}
\end{array}
$$

Bu performans metriklerini hesaplayabilmek için elde edilen sonuçların TP, TN, FP ve FN değerlerinin çıkarılması ve bir karmaşıklık matrisinde verilmesi gerekmektedir. Diğer bölümlerde de belirtildiği üzere önerilen yöntemde 5 farklı sınıflandırma algoritması kullanılmıştır. Bu kapsamda önerilen yaklaşım sonucunda elde edilen karmaşıklık matrisi Tablo 4'de verildiği gibidir.

Tablo 4. Önerilen Yöntem ile Elde Edilen Karmaşıklık Matris Sonuçları

\begin{tabular}{l|c|c|c|c}
\hline & TP & FP & FN & TN \\
\hline Linear SVM & 1947 & 110 & 35 & 1820 \\
\hline Quadratic SVM & 1949 & 108 & 24 & 1831 \\
\hline Cubic SVM & 1951 & 106 & 34 & 1821 \\
\hline Medium Gaussian SVM & 1949 & 108 & 23 & 1832 \\
\hline Coarse Gaussian SVM & 1942 & 115 & 46 & 1809 \\
\hline
\end{tabular}

\section{Tartışma}

Önerilen yöntemde, elde edilen özellik matrisi farklı SVM kernel yöntemleri kullanılarak sinıflandırılmış ve bu sınıflandırma işleminin sonucunda bazı performans metrikleri kullanılarak sonuçlar incelenmiştir. Tablo 4'de de sunulan karmaşıklık matrisi kullanılarak 5 farklı sınıflandırma yönteminin doğruluk, kesinlik, duyarlılık, geometrik ortalama ve f-skoru değerleri elde edilmiş olup, bu sonuçlar Tablo 5'de detaylı bir şekilde paylaşılmış̧ır.

Tablo 5. 5 Farklı Sinıflandırıcı için Elde Edilen Performans Metrikleri

\begin{tabular}{|l|c|c|c|c|c|c|}
\hline & & Doğruluk & Kesinlik & Duyarlılık & Geo. Ort. & F-Skor \\
\hline \multirow{4}{*}{$\begin{array}{l}\text { Linear } \\
\text { SVM }\end{array}$} & Max & 96,29 & 96,26 & 96,38 & 96,36 & 96,32 \\
\cline { 2 - 7 } & Min & 95,85 & 95,82 & 95,92 & 95,92 & 95,87 \\
\cline { 2 - 7 } & Mean & 96,03 & 96,00 & 96,11 & 96,09 & 96,05 \\
\cline { 2 - 7 } Quadratic & Std & 0,07 & 0,07 & 0,07 & 0,07 & 0,07 \\
\cline { 2 - 7 } SVM & Max & 96,62 & 96,60 & 96,72 & 96,70 & 96,66 \\
\cline { 2 - 7 } & Min & 96,24 & 96,21 & 96,33 & 96,31 & 96,27 \\
\cline { 2 - 7 } & Std & 96,41 & 96,39 & 96,51 & 96,49 & 96,45 \\
\hline \multirow{3}{*}{\begin{tabular}{l} 
Subic \\
\cline { 2 - 7 }
\end{tabular}} & Max & 9,07 & 0,07 & 0,08 & 0,07 & 0,07 \\
\cline { 2 - 7 } & Min & 95,42 & 96,39 & 96,5 & 96,49 & 96,45 \\
\cline { 2 - 7 } & Mean & 96,04 & 95,79 & 96,9 & 95,89 & 95,84 \\
\cline { 2 - 7 } & Std & 0,1 & 96,01 & 96,12 & 96,11 & 96,06 \\
\hline Medium & Max & 96,65 & 96,63 & 96,75 & 96,73 & 96,46 \\
\hline
\end{tabular}




\begin{tabular}{|l|c|c|c|c|c|c|}
\hline \multirow{3}{*}{$\begin{array}{l}\text { Gaussian } \\
\text { SVM }\end{array}$} & Min & 96,34 & 96,33 & 96,45 & 96,42 & 96,39 \\
\cline { 2 - 7 } & Mean & 96,52 & 96,50 & 96,62 & 96,6 & 96,56 \\
\cline { 2 - 7 } & Std & 0,05 & 0,05 & 0,05 & 0,05 & 0,05 \\
\hline \multirow{3}{*}{$\begin{array}{l}\text { Coarse } \\
\text { Gaussian }\end{array}$ SVM } & Max & 95,88 & 95,85 & 95,96 & 95,95 & 95,90 \\
\cline { 2 - 7 } & Min & 95,60 & 95,56 & 95,67 & 95,66 & 95,62 \\
\cline { 2 - 7 } & Mean & 95,75 & 95,72 & 95,83 & 95,82 & 95,78 \\
\cline { 2 - 7 } & Std & 0,05 & 0,05 & 0,05 & 0,05 & 0,05 \\
\hline
\end{tabular}

Tablo 5'den de görülebileceği üzere SVM sınıflandırma algoritması 5 farklı kernel yapısı için de yaklaşık \%96.5'in üzerinde performans göstermiştir. $\mathrm{Bu}$ durumun elde edilmesindeki temel etken, verilerin toplandıktan sonra çeşitli ön işlemlerden geçirilmesidir. Bu çerçevede ilk olarak ortalama havuzlama yöntemi kullanılarak görüntüde boyut azaltma işlemi yapılmış olup, daha sonrasında yönlendirilmiş gradyan histogramı ile özellik çıkarımı uygulanmıştır. Çok sayıda elde edilen özellikler ki-kare yöntemi kullanılarak azaltılmış ve sadece en ağırlıklı öz niteliklerin sınıflandırıcı da kullanılması sağlanmıştır. Son olarak elde edilen özellik matrisi SVM tabanlı sinıflandırıcıya verilmiş ve en başta toplanan asfalt görüntüleri sağlıklı ve arızalı olacak şekilde 2 grupta sınıflandırılmıştır. Elde edilen performans metrikleri de önerilen yöntemin başarılı ve uygulanabilir olduğunu ispatlamaktadır.

\section{Sonuçlar ve Gelecek Çalışmalar}

Taşımacılık sektöründe en sık kullanılan yöntem karayolu taşımacılığıdır. Gerek yolcu gerekse yük taşımacılığında aktif bir şekilde karayollarının kullanılması, zaman içerisinde bu yolların bozulmasına sebebiyet vermektedir. Günümüzde karayollarının kaplamasında kullanılan temel hammadde asfalttrr. Fakat asfalt yapısı gereği kullanıma ve çevresel koşullara bağlı olarak zaman içerisinde yıpranmakta ve yüzeyde bozulma, çökme, çatlama gibi durumlar meydana gelmektedir. Bu yıpranmaların kötü sonuçlara sebebiyet vermeden tespit edilmesi ve onarılması özellikle sürüş güvenliği açısından büyük önem arz etmektedir. Ayrıca bozulmanın gerçekleştiği ilk aşamalarda bu onarımların gerçekleştirilmesi onarım maliyetlerini de ciddi derece de azaltmaktadır.
Gerçekleştirilen bu çalışma ile asfalt yüzeylerde meydana gelen bozulmaların tam otomatik bir şekilde tespit edilmesi ve sağlıklı-arızalı kategorilere göre sınıflandırılması sağlanmıştır. Hareket halindeki bir araca monte edilen kamera sayesinde çeşitli asfalt görüntüleri toplanmış ve bir veri seti oluşturulmuştur. Oluşturulan bu veri setine bazı ön işlemler uygulanmış ve görüntülerin boyutu küçültülmüştür. Daha sonraki aşamada veri setine özellik çıkarım işlemi uygulanmış ve elde edilen özelliklerden en önemlileri seçilmiştir. Son olarak SVM tabanlı sınıflandırma işlemi uygulanmış ve neticesinde yaklaşık olarak \%96.5 oranında bir doğruluk elde edilmiştir. Çalışma kapsamında herhangi bir kullanıcı müdahalesine ihtiyaç duymayan otomatik asfalt durum izleme yaklaşımı geliştirilmiştir. Yüksek doğrulukla çalışan bu yöntem ile bozulmaya başlamış veya bozulmuş asfaltların durumları çok hızlı bir şekilde değerlendirilebilecek ve erken müdahale kabiliyeti sağlanabilecektir. Bu sayede yüksek onarım maaliyetleri azaltılmış olacaktır.

Önerilen bu yaklaşımın bir sonraki aşamasında arızalı asfalt görüntülerinin literatürde de yer alan çeşitli arıza türlerine göre sınıflandırılması hedeflenmektedir. Gelecek çalışmalarda arıza türlerinin de yine kullanıcı müdahalesine gerek kalmadan tespit edilmesi ve etiketlenmesi planlanmaktadır. Ayrıca akıllı şehir kapsamında toplu taşıma araçlarına yerleştirilecek kamera ve gömülü sistem ile yollardaki asfalt arızaları tespit edilecektir. Üstelik arıza boyutu, arıza türü ve konumu merkeze iletilerek harita üzerinden arızanın bulunduğu bölge analiz edilecektir. Bu noktada, gelecek çalışmalarda geliştirilebilecek sisteme yönelik bu öneri Şekil 4 'te gösterilmiştir.

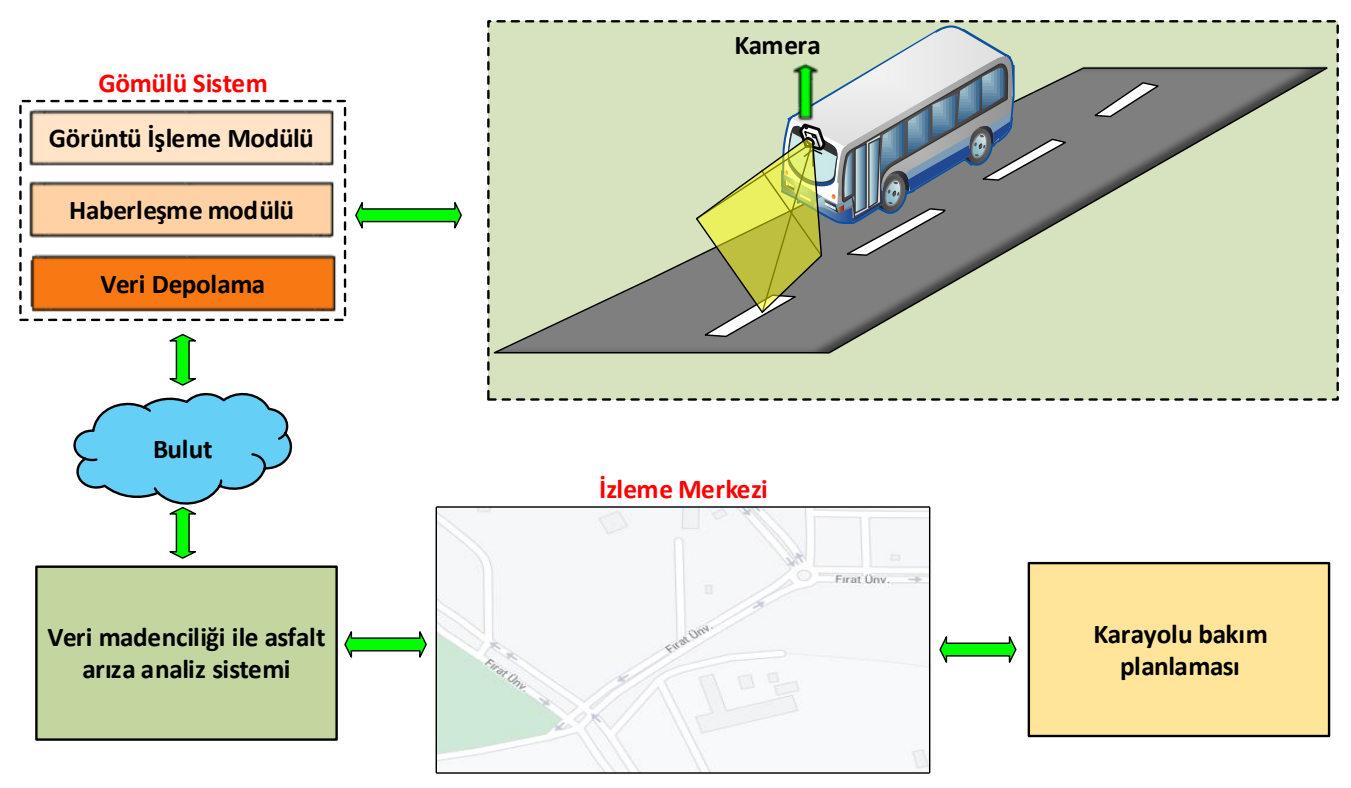

Şekil 4. Gelecek Çalışmalara Yönelik Sistem Geliştirme Önerisi 


\section{Kaynakça}

Alpaslan, N., Talu, M. F., Gül, M., \& Yiğitcan, B. (2012). Hog Tabanlı YSA Kullanılarak Yă̆lı Karaciğer Tedavisindeki Ilaç Etkinliklerinin Hesaplanmast.

Baygin, M. (2019). Classification of Text Documents based on Naive Bayes using N-Gram Features. 2018 International Conference on Artificial Intelligence and Data Processing, IDAP 2018. https://doi.org/10.1109/IDAP.2018.8620853

Baygin, N., Baygin, M., \& Karakose, M. (2019). A SVM-PSO Classifier for Robot Motion in Environment with Obstacles. 2019 International Conference on Artificial Intelligence and Data Processing Symposium, IDAP 2019. https://doi.org/10.1109/IDAP.2019.8875921

Bello-Salau, H., Aibinu, A. M., Onwuka, E. N., Dukiya, J. J., Onumanyi, A. J., \& Ighagbon, A. O. (2016). Development of a laboratory model for automated road defect detection. Journal of Telecommunication, Electronic and Computer Engineering, 8(9), 97-101.

Cheng, J., Xiong, W., Chen, W., Gu, Y., \& Li, Y. (2019). Pixellevel Crack Detection using U-Net. IEEE Region 10 Annual International Conference, Proceedings/TENCON, 2018-October(October), $462-466$. https://doi.org/10.1109/TENCON.2018.8650059

Chia, M. Y., Huang, Y. F., \& Koo, C. H. (2020). Support vector machine enhanced empirical reference evapotranspiration estimation with limited meteorological parameters. 175(April).

Fan, Z., Li, C., Chen, Y., Mascio, P. Di, Chen, X., Zhu, G., \& Loprencipe, G. (2020). Ensemble of Deep Convolutional Neural Networks and Measurement. 1-14.

Gopalakrishnan, K., Khaitan, S. K., Choudhary, A., \& Agrawal, A. (2017). Deep Convolutional Neural Networks with transfer learning for computer vision-based data-driven pavement distress detection. Construction and Building Materials, 157 , 322-330.

https://doi.org/10.1016/j.conbuildmat.2017.09.110

Jahanshahi, M. R., Jazizadeh, F., Masri, S. F., \& Becerik-Gerber, B. (2013). Unsupervised approach for autonomous pavement-defect detection and quantification using an inexpensive depth sensor. Journal of Computing in Civil Engineering, 27(6), 743-754. https://doi.org/10.1061/(ASCE)CP.1943-5487.0000245

Karakaya, F., Altun, H., \& Çavuşlu, A. (2009). Gerçek Zamanlı Nesne Tanıma Uygulamalar için HOG Algoritmasının FPGA Tabanlı Gömülü Sistem Uyarlaması. 508-511.

Kawano, M., Mikami, K., Yokoyama, S., Yonezawa, T., \& Nakazawa, J. (2017). Road marking blur detection with drive recorder. Proceedings - 2017 IEEE International Conference on Big Data, Big Data 2017, 2018-Janua, 4092-4097.

https://doi.org/10.1109/BigData.2017.8258427

Li, B., Wang, K. C. P., Zhang, A., Yang, E., Wang, G., Li, B., Wang, K. C. P., Zhang, A., \& Yang, E. (2020). Automatic classification of pavement crack using deep convolutional neural network. 8436. https://doi.org/10.1080/10298436.2018.1485917

Majidifard, H., Adu-Gyamfi, Y., \& Buttlar, W. G. (2020). Deep machine learning approach to develop a new asphalt pavement condition index. Construction and Building Materials, 247, 118513. https://doi.org/10.1016/j.conbuildmat.2020.118513

Majidifard, H., Jin, P., Adu-Gyamfi, Y., \& Buttlar, W. G. (2020).
Pavement Image Datasets: A New Benchmark Dataset to Classify and Densify Pavement Distresses. Transportation Research Record, 2674(2), 328-339. https://doi.org/10.1177/0361198120907283

Mandal, V., Uong, L., \& Adu-Gyamfi, Y. (2019). Automated Road Crack Detection Using Deep Convolutional Neural Networks. Proceedings - 2018 IEEE International Conference on Big Data, Big Data 2018, 5212-5215. https://doi.org/10.1109/BigData.2018.8622327

Nguyen, T. S., Begot, S., Duculty, F., \& Avila, M. (2011). FreeForm Anisotropy: A New Method for Crack Detection on Pavement Surface Images. 1, 1069-1072.

Shahnazari, H., Tutunchian, M. A., Mashayekhi, M., \& Amini, A. A. (2012). Application of Soft Computing for Prediction of Pavement Condition Index. December, 1495-1506. https://doi.org/10.1061/(ASCE)TE

Shi, Y., Cui, L., Qi, Z., Meng, F., \& Chen, Z. (2016). Automatic Road Crack Detection Using Random Structured Forests. IEEE Transactions on Intelligent Transportation Systems, 17(12), 1-12.

Some, L. (2016). Automatic image-based road crack detection methods. LIENE SOME KTH ROYAL INSTITUTE OF TECHNOLOGY SCHOOL OF ARCHITECTURE AND THE BUILT ENVIRONMENT. http://www.divaportal.org/smash/record.jsf?pid=diva2\%3A945233\&dswid $=-7141 \% 0 \mathrm{Ahttp}: / / \mathrm{kth} \cdot \mathrm{diva}-$

portal.org/smash/record.jsf?pid=diva2\%3A945233\&dswid $=1058 \% 0$ Ahttp://www.divaportal.org/smash/get/diva2:945233/FULLTEXT03.pdf

Xu, W., \& Tang, Z. (2013). PAVEMENT CRACK DETECTION BASED ON SALIENCY AND STATISTICAL FEATURES School of Computer Science and Engineering , Nanjing University of Science and Technology, China. 4093-4097.

Yaman, O., Yetis, H., \& Karakose, M. (2020). Band Reducing Based SVM Classification Method in Hyperspectral Image Processing. Zooming Innovation in Consumer Technologies Conference (ZINC), 21-25.

Yazıcı, B., Yaslı, F., Gürleyik, H. Y., \& Turgut, U. O. (n.d.). Veri Madenciliğinde Özellik Seçim Tekniklerinin Bankacılık Verisine Uygulanması Üzerine Araştırma ve Karşılaştırmalı Uygulama. 72-83.

Zalama, E., Jaime, G., \& Medina, R. (2014). Road Crack Detection Using Visual Features Extracted by Gabor Filters. 29, 342-358. https://doi.org/10.1111/mice.12042

Zhang, D., Li, Q., Chen, Y., Cao, M., He, L., \& Zhang, B. (2017). An efficient and reliable coarse-to-fine approach for asphalt pavement crack detection. Image and Vision Computing, 57, 130-146. https://doi.org/10.1016/j.imavis.2016.11.018 